\section{DISCUSSION}

Cavernoma is a benign tumor and it is considered a dysplasia of the vessels-forming mesoderm ${ }^{4}$. Cavernous hemangiomas in the vertebral, extradural, intradural extramedullary and intramedullary spaces are responsible for 3 to $16 \%$ of spinal vascular anomalies ${ }^{4,5}$.

Extradural cavernous hemangioma represent 4\% of all spinal epidural lesions ${ }^{5}$. Modern diagnostic imaging techniques are increasing the number of diagnosis and its frequency may be more than previously reported in the medical literature ${ }^{5}$.

There are four clinical syndromes described: slow and progressive spinal cord syndrome, which is the most common form; acute spinal cord syndrome; back pain; and radiculopathy ${ }^{3}$.

Imaging diagnostic exams such as spine $\mathrm{X}$-rays, myelography, CT and MRI are important for evaluating the relationship of the lesion with the surrounding anatomic structures ${ }^{1}$. Currently, MRI is the modality of choice ${ }^{5}$.

The treatment for these lesions is total removal of the tumor with microsurgical technique ${ }^{1}$.

\section{REFERENCES}

1. Hatiboglu MA, Iplikcioglu AC, Ozcan D. Epidural spinal cavernous hemangioma-case Report. Neurol Med Chir (Tokyo) 2006;46:455-458.

2. Goyal A, Singh AK, Gupta V, Tatke M. Spinal epidural cavernous haemangioma:a case report and review of literature. Spinal Cord 2002;40: 200-202.

3. Zevgaridis D, Buttner A, Weis S, Hamburger C, Reulen HJ. Spinal epidural cavernous hemangiomas. Report of three cases and review of the literature. J Neurosurg 1988;88:903-908.

4. Saringer W, Nobauer I, Haberler C, Ungersbock K. Extraforaminal, thoracic, epidural cavernous hemangioma:case report with analysis of magnetic resonance imaging characteristics and review of the literature. Acta Neurochir (Wien) 2001;43:1293-1297.

5. Santoro A, Piccirilli M, Bristot R, Norcia V, Salvati M, Delfini R. Extradural spinal cavernous angiomas: report of seven cases. Neurosurg Rev 2005;28: 313-319.

\section{HEMANGIOMA CAVERNOSO EXTRADURAL DA COLUNA TORÁCICA}

Neurosurgical Unit, Hospital de Clínicas de Porto Alegre, Porto Alegre RS, Brazil: ${ }^{1}$ Head of Neurosurgical Unit, Associate Professor of Neurosurgery, FAMED, UFRGS; ${ }^{2}$ Resident of Neurosurgery.

Correspondence: Apio Antunes - Unidade de Neurocirurgia / Serviço de Neurologia do HCPA - Rua Ramiro Barcelos $2350 / 2^{\circ}$ andar - 90035-903 Porto Alegre RS - Brasil. E-mail: apioantunes@gmail.com

Received 13 February 2011. Received in final form 31 November 2011. Accepted 7 April 2011.

\title{
Bilateral traumatic avulsion of abducens nerve
}

\author{
Bruno S.C. Lopes ${ }^{1}$, Lazaro L.F. do Amaral', Higor G. Bezerra', \\ Ricardo M. Rogério', Antônio A. Zambon²
}

A 45-year-old previously healthy woman suffered a head trauma with neck hyperextension during bike exercise, losing consciousness for about 24 hours. Upon awakening, she presented bilateral lateral gaze palsy and convergent strabismus (Fig 1). No bone fracture was detected on CT studies (not shown). This clinical picture persisted unchanged for over one year and a MRI study done at our service showed bilateral avulsion of the sixth cranial nerve using FIESTA sequence (Fig 2A, B, C and D).

The abducens innervates the lateral rectus muscle, which is responsible for the horizontal lateral movement of the ocular globe. It has a long course, beginning at its nucleus, on the ventral pons, going through the pre-pontine cistern to its dural entry point on the petroclival region, coursing through Dorello's canal, beneath petroesphenoidal ligament, where it is covered by an envelope composed of one dural layer and one arachnoidal layer ${ }^{1}$ to the cavernous sinus, lateral to the internal carotid artery, reaching the superior orbital fissure and orbital apex. This long course makes it more susceptible to injuries.

Various different diseases can cause sixth nerve palsy, neoplasic and traumatic etiologies being more common in children, while vascular and idiopathic are responsible for the majority of cases in adult population ${ }^{2}$.

Traumatic injuries of abducens nerve are a wellknown consequence of severe head trauma, reported in

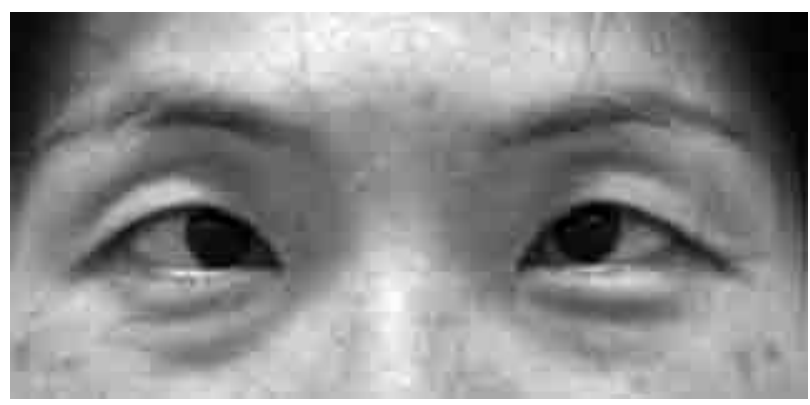

Fig 1. Convergent strabismus evidenced at physical examination 1-year after head trauma. 

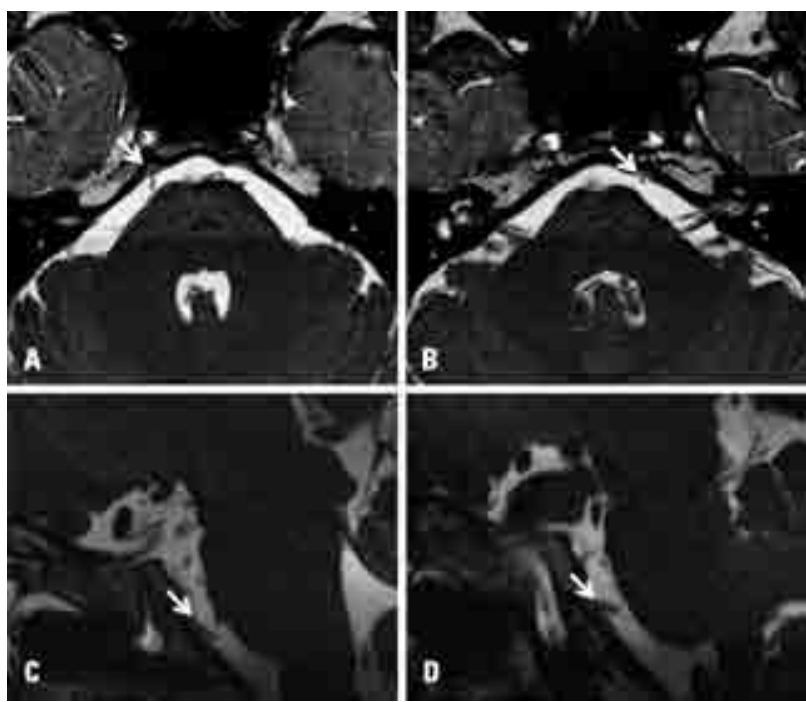

Fig 2. MRI study 1-year after trauma showing discontinuity on the cisternal segment of the $\mathrm{VI}$ nerve (complete avulsion) on the right $[A$ and $C]$ and on the left $[B$ and $D]$. Oblique axial $[A$ and $B]$ and oblique sagital [C and D] FIESTA reformatted images.

$1-2,7 \%$ of the cases, with or without associated cervical or skull base fracture ${ }^{3}$. Usually, the mechanism of injury is contusion/stretching along its course and vertical displacement (downward and/or upward) of the brain is supposed to be the cause of these lesions $s^{4}$. Two points along the nerve course are described as the most prone to injury ${ }^{3-5}$ : the dural entry point (during upward displacement) and the petrous apex (during downward displacement). Since these two movements are usually associated on severe head trauma, these two points likely work together to cause the lesion.

In our case, with a MRI study acquired on 1.5 tesla equipment (GE Medical systems - Milwaukee), using FIESTA sequence post processed in dedicated workstation, we observed bilateral sixth nerve discontinuity along its pre-pontine course, detached from the pons, at the pontmedullary sulcus level. The other cranial nerves had preserved morphology. There were no signs of bone fracture, brainstem or orbital muscle lesions.

FIESTA (different names are used for similar technique by other manufacturers, like BALANCED FFE and 3D-CISS, for example) is a magnetic resonance sequence heavily T2-weighted, capable of acquiring very thin slices, allowing reformation in all three planes, optimal for analyzing morphologic features of structures next to CSF containing spaces, like basal cisterns.

In the presented case, one year after trauma, there was still unchanged ophthalmoplegia and a MRI study showed bilateral complete abducens nerve avulsion. As far as we know, no previous report has showed, with imaging studies, this consequence of head trauma.

\section{REFERENCES}

1. Kenichiro $\mathrm{O}$, Arai H, Endo T, et al. Detailed MR imaging anatomy of the abducent nerve: evagination of CSF into Dorello canal. AJNR Am J Neuroradiol 2004;25:623-626.

2. Berlit P, Reinhardt-Eckstein J, Krause KH, et al. Isolated abducens paralysis: a retrospective study of 165 patients. Fortschr Neurol Psychiatr 1989; 57:32-40.

3. Arias MJ. Bilateral traumatic abducens nerve palsy without skull fracture and with cervical spine fracture: case report and review of the literature. Neurosurgery 1985;16:232-234.

4. Hollis G. Sixth cranial nerve palsy following closed head injury in a child. J Accid Emerg Med 1997;4:172-175.

5. Advani RM, Baumann MR. Bilateral sixth nerve palsy after head trauma. Ann Emerg Med 2003;41:27-31.

\section{AVULSÃO TRAUMÁTICA BILATERAL DO NERVO ABDUCENTE}

'Department of Neuroradiology, Medimagem, Hospital Beneficência Portuguesa e Hospital Santa Catarina, São Paulo SP, Brazil; ${ }^{2}$ Department of Neurology, Hospital A.C. Camargo, São Paulo SP, Brazil.

Correspondence: Bruno S.C. Lopes - Rua Martiniano de Carvalho 669 / 1006 01321-900 São Paulo SP - Brasil. E-mail : brunosclopes@hotmail.com.

Received 1 March 2011. Received in final form 28 March 2011. Accepted 13 April 2011. 